\title{
Association between Depression and Risk Factors as Obesity and Type 2 Diabetes Mellitus \\ Ahmed A. Zaghlol ${ }^{1}$, Khaled M. Hadhoud ${ }^{1}$, Amira Fouad ${ }^{2}$, Ahmed Mohamed Eldernawi*1, Mohamed R. Herzalla ${ }^{1}$
}

\author{
Departments of ${ }^{1}$ Internal Medicine and ${ }^{2}$ Psychiatry, Faculty of Medicine, Zagazig University, Egypt. \\ *Corresponding author: Ahmed Mohamed Eldernawi, Email: docahmed1989@gmail.com
}

\begin{abstract}
Background: the prevalence of mood and anxiety disorders is higher among persons living with diabetes compared to those without diabetes. Numerous studies have demonstrated that both obesity and metabolic disorders are associated with depression. This study aimed to confirm the association between depression and risk factors as obesity and type 2 diabetes mellitus. Subjects and methods: This comparative cross-sectional study was carried out on 90 adults attending to the Diabetes outpatient clinic in Internal Medicine Department, Faculty of Medicine, Zagazig University Hospitals. They were divided into three groups, 30 patients with type 2 diabetes mellitus with normal body mass index (BMI), 30 obese non-diabetic individuals and 30 obese type 2 diabetic patients. Full medical history, clinical examination, laboratory investigation and assessment of depression were performed.

Result: Age was $51.60 \pm 14.28,42.26 \pm 12.21$ and $51.93 \pm 9.89$ respectively and Group B it was significantly younger than other two groups with no significant difference between them. No significant difference was found between groups regarding disease duration or diabetes mellitus (DM) treatment and also complication but regarding comorbidity Group C was significantly associated with comorbidity. Group A was significantly lower regarding Beck Depression Inventory and overall depression was significantly associated with group B and Group C as it was $30.0 \%$ and $46.7 \%$ respectively. Grade and overall depression were significantly associated with BMI $>35$ group.

Conclusion: Type 2 diabetes mellitus and morbid obesity (BMI > 35) were associated with high prevalence of depression. It is evident that several modifiable and non-modifiable risk factors play an important role in the pathogenesis of diabetes and depression among population.
\end{abstract}

Keywords: Depression, Diabetes mellitus, Metabolic diseases, Obesity.

\section{INTRODUCTION}

Diabetes mellitus is a chronic-degenerative disease, characterized by high levels of blood glucose. It has been estimated that diabetes mellitus type 2 affects about 246 million people in the world; nevertheless, incidence varies among countries. The International Diabetes Federation has anticipated an increase of 366 million people by 2030, giving a total of 552 million people with diabetes type 2 in the world (1). The prevalence of type 2 diabetes is increasing around the world, affecting approximately 422 million people in $2014^{(2)}$.

In Egypt, the incidence of diabetes among adults between the ages of 20 and 79 is around 15.56 percent, with an annual diabetes-related death of 86,478. The International Diabetes Federation (IDF) estimated 7.5 million people with diabetes in 2013 and about 2.2 million people with pre-diabetes in Egypt ${ }^{(3)}$.

The association between type 2 diabetes and depression is bidirectional with depression increasing the risk of type 2 diabetes and type 2 diabetes increasing the risk of depression ${ }^{(4)}$.

Obesity is known to be the main risk factor for a number of non-communicable diseases like cardiovascular disease and type 2 diabetes. Besides, it causes diverse psychological problems or various physical disabilities. Type 2 diabetes is most strongly associated with obesity, and the prevalence of obesityrelated diabetes is expected to double to 300 million by 2025. This close relationship also led to the connotation 'diabesity', highlighting the fact that the majority of individuals with diabetes are overweight or obese ${ }^{(5)}$.

Patients with diabetes mellitus type 2 , often present a careless attitude towards their disease, resulting in metabolic decompensation, with high and low glycemic levels which could trigger mood alterations. Diabetes mellitus 2 is also associated with a higher risk of comorbid depression compared with the general population. It has been suggested that diabetes type 2 could be conditioned by depression, anxiety or anguish; nevertheless, the reason for this association is not clear ${ }^{(\boldsymbol{6})}$.

This study aimed to confirm association between depression and risk factors as obesity and type 2 diabetes mellitus.

\section{PATIENTS AND METHODS}

This is comparative cross sectional study, which was carried out on 90 adults attending to the Diabetes outpatient clinic in Internal Medicine Department, Faculty of Medicine, Zagazig University Hospitals, from April 2021 to July 2021. They were divided into Three Groups, 30 patients with type 2 Diabetes Mellitus with normal BMI, 30 obese non-diabetic individuals and 30 obese type 2 Diabetic patients.

Inclusion criteria: Age: adults (aged 18 years and over), sex: both male and female, and obese Individuals, type 2 diabetes patients with normal BMI 
(duration of diabetes between 5-15 years) and obese patients with type 2 diabetes (duration of diabetes between $5-15$ years).

Exclusion criteria: Age less than 18 years old, type 1 diabetes, incomplete Beck Depression Inventory (BDI), Montreal Cognitive Assessment (MoCA) or clinical data, pregnancy and post menopause, inability or refusal to provide informed consent, alcoholic and drug abuse, and duration of diabetes less than 5 years and more than 15 years.

All groups were subjected to the full medical history in a positive family history of diabetes, lifestyle factors and physical activity, clinical examination and clinical investigation. All individuals were asked to avoid smoking and caffeine intake for 8 to 10 hours, while antidiabetic medications withheld and administered to the participants at the end of the examination.

Body mass index (BMI) was calculated as the weight in kilograms divided by the square of height in meters. Waist circumference measured at the minimal abdominal girth between the rib cage and the iliac crest.

\section{Beck Depression Inventory (BDI) evaluation:}

All participants had a BDI evaluation, The Beck Depression Inventory is a 21-question multiple-choice self-report inventory for measuring depression severity. A value of 0 to 3 is assigned for each answer and the depression severity is determined by the total score, higher scores indicate more severe depressive symptoms. BDI scores of $0-9,10-18,19-29$ and 30-63 are considered as minimal, mild, moderate and severe depression, respectively ${ }^{(\mathbf{1 0})}$.

\section{Ethical approval:}

The study was approved by the Ethical Committee of Zagazig Faculty of Medicine. An informed consent was obtained from all patients in this research. Every patient received an explanation for the purpose of the study. All given data were used for the current medical research only. This work has been carried out in accordance with The Code of Ethics of the World Medical Association (Declaration of Helsinki) for studies involving humans.

\section{Statistical analysis}

Data analyzed using Microsoft Excel software. Data were then imported into Statistical Package for the Social Sciences (SPSS version 20.0) software for analysis. According to the type of data, qualitative were represented as number and percentage while quantitative data were represented by mean $\pm \mathrm{SD}$. Chi square test $\left(\mathrm{X}^{2}\right), \mathrm{t}$ test, and one-waybANOVA were used. $\mathrm{P}$ value was set at $<0.05$ for significant results and $<0.001$ for high significant result.

\section{RESULTS}

The present study showed no significant difference among groups regarding the demographic data (Table 1).

Table (1): Demographic data of the studied groups

\begin{tabular}{|c|c|c|c|c|c|c|c|}
\hline \multicolumn{3}{|c|}{ 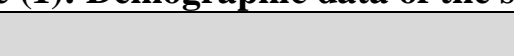 } & \multirow{2}{*}{\begin{tabular}{|c|} 
Group A \\
$51.60 \pm 14.28$ \\
\end{tabular}} & Group B & Group C & $\mathbf{F} / \mathbf{X}^{2}$ & $\mathbf{P}$ \\
\hline \multicolumn{3}{|l|}{ Age } & & $42.26 \pm 12.21 \#$ & $51.93 \pm 9.89$ & 6.007 & $0.004 *$ \\
\hline \multirow[t]{4}{*}{ Gender } & \multirow[t]{2}{*}{ Female } & $\mathbf{N}$ & 14 & 16 & 16 & & \\
\hline & & $\%$ & $46.7 \%$ & $53.3 \%$ & $53.3 \%$ & & \\
\hline & \multirow[t]{2}{*}{ Male } & $\mathbf{N}$ & 16 & 14 & 14 & 0.36 & 0.84 \\
\hline & & $\%$ & $53.3 \%$ & $46.7 \%$ & $46.7 \%$ & & \\
\hline \multirow{4}{*}{$\begin{array}{l}\text { Education } \\
\text { level }\end{array}$} & \multirow[t]{2}{*}{ High } & $\mathbf{N}$ & 18 & 22 & 16 & & \\
\hline & & $\%$ & $60.0 \%$ & $73.3 \%$ & $53.3 \%$ & & \\
\hline & \multirow[t]{2}{*}{ Low } & $\mathbf{N}$ & 12 & 8 & 14 & 2.65 & 0.27 \\
\hline & & $\%$ & $40.0 \%$ & $26.7 \%$ & $46.7 \%$ & & \\
\hline \multirow[t]{4}{*}{ Smoking } & \multirow[t]{2}{*}{$-V E$} & $\mathbf{N}$ & 24 & 22 & 24 & & \\
\hline & & $\%$ & $80.0 \%$ & $73.3 \%$ & $80.0 \%$ & & \\
\hline & \multirow[t]{2}{*}{$+\mathrm{VE}$} & $\mathbf{N}$ & 6 & 8 & 6 & 0.51 & 0.77 \\
\hline & & $\%$ & $20.0 \%$ & $26.7 \%$ & $20.0 \%$ & & \\
\hline \multirow[t]{6}{*}{ Employment } & \multirow[t]{2}{*}{ Not } & $\mathbf{N}$ & 8 & 4 & 14 & & \\
\hline & & $\%$ & $26.7 \%$ & $13.3 \%$ & $46.7 \%$ & & \\
\hline & \multirow{2}{*}{$\begin{array}{l}\text { Worke } \\
\text { d }\end{array}$} & $\mathbf{N}$ & 18 & 26 & 16 & 16.66 & $0.002 *$ \\
\hline & & $\%$ & $60.0 \%$ & $86.7 \%$ & $53.3 \%$ & & \\
\hline & \multirow{2}{*}{ Retired } & $\mathbf{N}$ & 4 & 0 & 0 & & \\
\hline & & $\%$ & $13.3 \%$ & $0.0 \%$ & $0.0 \%$ & & \\
\hline \multirow{2}{*}{\multicolumn{2}{|c|}{ Total }} & $\mathbf{N}$ & 30 & 30 & 30 & & \\
\hline & & $\%$ & $100.0 \%$ & $100.0 \%$ & $100.0 \%$ & & \\
\hline
\end{tabular}

\#: Group significantly lower than other groups, *: Significant difference 
Group C was significantly associated with comorbidity (Table 2).

Table (2): Disease characters for diabetic groups only

\begin{tabular}{|c|c|c|c|c|c|c|}
\hline \multicolumn{3}{|c|}{ 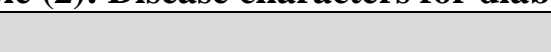 } & Group A & Group C & $t / X^{2}$ & $\overline{\mathbf{P}}$ \\
\hline \multicolumn{3}{|c|}{ Disease duration } & $9.06 \pm 3.13$ & $8.66 \pm 2.88$ & 0.223 & 0.639 \\
\hline \multirow{4}{*}{$\begin{array}{l}\text { Diabetes } \\
\text { mellitus } \\
\text { Treatment }\end{array}$} & \multirow[t]{2}{*}{ Insulin } & $\mathbf{N}$ & 14 & 10 & & \\
\hline & & $\%$ & $46.7 \%$ & $33.3 \%$ & & \\
\hline & \multirow[t]{2}{*}{ OHD } & $\mathbf{N}$ & 16 & 20 & 1.11 & 0.29 \\
\hline & & $\%$ & $53.3 \%$ & $66.7 \%$ & & \\
\hline \multirow[t]{4}{*}{ Comorbidities } & \multirow[t]{2}{*}{$-V E$} & $\mathbf{N}$ & 14 & 8 & & \\
\hline & & $\%$ & $46.7 \%$ & $26.7 \%$ & & \\
\hline & \multirow[t]{2}{*}{$+\mathrm{VE}$} & $\mathbf{N}$ & 16 & 22 & 2.58 & 0.11 \\
\hline & & $\%$ & $53.3 \%$ & $73.3 \%$ & & \\
\hline \multirow[t]{4}{*}{ Complications } & \multirow[t]{2}{*}{$-V E$} & $\mathbf{N}$ & 14 & 18 & & \\
\hline & & $\%$ & $46.7 \%$ & $60.0 \%$ & & \\
\hline & \multirow[t]{2}{*}{$+\mathrm{VE}$} & $\mathbf{N}$ & 16 & 12 & 1.07 & 0.30 \\
\hline & & $\%$ & $53.3 \%$ & $40.0 \%$ & & \\
\hline \multirow{2}{*}{\multicolumn{2}{|c|}{ Total }} & $\mathbf{N}$ & 30 & 30 & & \\
\hline & & $\%$ & $100.0 \%$ & $100.0 \%$ & & \\
\hline
\end{tabular}

OHD: Oral hypoglycemic drugs

Group A was significantly lower as regard Beck Depression Inventory and overall depression was significantly associated with group B and Group C (Table 3).

Table (3): Depression distribution among studied groups according to Beck Depression Inventory (BDI)

\begin{tabular}{|c|c|c|c|c|c|c|c|}
\hline & 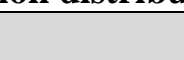 & & Group A & Group B & Group C & $\mathbf{F} / \mathbf{X}^{2}$ & $\mathbf{P}$ \\
\hline Beck Depre & n Inventory & & $8.86 \pm 3.12$ & $12.43 \pm 3.57$ & $13.93 \pm 4.58$ & 2.208 & $0.022 *$ \\
\hline Depression & No & $\mathbf{N}$ & 24 & 21 & 16 & & \\
\hline & & $\%$ & $80.0 \%$ & $70.0 \%$ & $53.3 \%$ & & \\
\hline & Mild & $\mathbf{N}$ & 2 & 2 & 6 & & \\
\hline & & $\%$ & $6.7 \%$ & $6.7 \%$ & $20.0 \%$ & & \\
\hline & Moderate & $\mathbf{N}$ & 2 & 6 & 8 & 10.3 & 0.11 \\
\hline & & $\%$ & $6.7 \%$ & $20.0 \%$ & $26.7 \%$ & & \\
\hline & Severe & $\mathbf{N}$ & 2 & 1 & 0 & & \\
\hline & & $\%$ & $6.7 \%$ & $3.3 \%$ & $0.0 \%$ & & \\
\hline Depression & No & $\mathbf{N}$ & 24 & 21 & 16 & & \\
\hline & & $\%$ & $80.0 \%$ & $70.0 \%$ & $53.3 \%$ & & \\
\hline & Yes & $\mathbf{N}$ & 6 & 9 & 14 & 4.98 & 0.08 \\
\hline & & $\%$ & $20.0 \%$ & $30.0 \%$ & $46.7 \%$ & & \\
\hline Total & & $\mathbf{N}$ & 30 & 30 & 30 & & \\
\hline & & $\%$ & $100.0 \%$ & $100.0 \%$ & $100.0 \%$ & & \\
\hline
\end{tabular}

\#: Group significantly lower than other groups, *: Significant difference 
Grade and overall depression were significantly associated with BMI $>35$ group (Table 4).

Table (4): Depression distribution between BMI $<35$ and $>35$ according to Beck Depression Inventory (BDI)

\begin{tabular}{|c|c|c|c|c|c|c|c|}
\hline \multicolumn{4}{|c|}{ Group } & \multicolumn{2}{|c|}{ BMI } & \multirow[t]{3}{*}{$\mathrm{X}^{2}$} & \multirow[t]{2}{*}{$\mathbf{P}$} \\
\hline & & & & $<35$ & $>35$ & & \\
\hline \multirow[t]{14}{*}{ Group B } & \multirow[t]{8}{*}{ Depression } & \multirow[t]{2}{*}{ No } & $\mathbf{N}$ & 10 & 11 & & \\
\hline & & & $\%$ & $100.0 \%$ & $55.0 \%$ & & \\
\hline & & \multirow[t]{2}{*}{ Mild } & $\mathbf{N}$ & 0 & 2 & & \\
\hline & & & $\%$ & $0.0 \%$ & $10.0 \%$ & & \\
\hline & & \multirow[t]{2}{*}{ Moderate } & $\mathbf{N}$ & 0 & 6 & 6.43 & 0.09 \\
\hline & & & $\%$ & $0.0 \%$ & $30.0 \%$ & & \\
\hline & & \multirow[t]{2}{*}{ Severe } & $\mathbf{N}$ & 0 & 1 & & \\
\hline & & & $\%$ & $0.0 \%$ & $5.0 \%$ & & \\
\hline & \multirow[t]{4}{*}{ Depression } & \multirow[t]{2}{*}{$-\mathrm{VE}$} & $\mathbf{N}$ & 10 & 11 & & \\
\hline & & & $\%$ & $100.0 \%$ & $55.0 \%$ & & \\
\hline & & \multirow{2}{*}{$+\mathrm{VE}$} & $\mathbf{N}$ & 0 & 9 & 6.4 & $0.01 *$ \\
\hline & & & $\%$ & $0.0 \%$ & $45.0 \$$ & & \\
\hline & \multirow{2}{*}{\multicolumn{2}{|c|}{ Total }} & $\mathbf{N}$ & 10 & 20 & & \\
\hline & & & $\%$ & $100.0 \%$ & $100.0 \%$ & & \\
\hline \multirow[t]{14}{*}{ Group C } & \multirow[t]{8}{*}{ Depression } & \multirow[t]{2}{*}{ No } & $\mathbf{N}$ & 12 & 4 & & \\
\hline & & & $\%$ & $85.7 \%$ & $25.0 \%$ & & \\
\hline & & \multirow[t]{2}{*}{ Mild } & $\mathbf{N}$ & 2 & 4 & & \\
\hline & & & $\%$ & $14.3 \%$ & $25.0 \%$ & & \\
\hline & & \multirow[t]{2}{*}{ Moderate } & $\mathbf{N}$ & 0 & 8 & 12.5 & $0.002 *$ \\
\hline & & & $\%$ & $0.0 \%$ & $50.0 \%$ & & \\
\hline & & \multirow[t]{2}{*}{ Severe } & $\mathbf{N}$ & 0 & 0 & & \\
\hline & & & $\%$ & $0.0 \%$ & $0.0 \%$ & & \\
\hline & \multirow[t]{4}{*}{ Depression } & \multirow[t]{2}{*}{$-V E$} & $\mathbf{N}$ & 12 & 4 & & \\
\hline & & & $\%$ & $85.7 \%$ & $25.0 \%$ & 11.06 & $0.0009 * *$ \\
\hline & & \multirow[t]{2}{*}{$+\mathrm{VE}$} & $\mathbf{N}$ & 2 & 12 & & \\
\hline & & & $\%$ & $14.3 \%$ & $75.0 \%$ & & \\
\hline & \multirow{2}{*}{\multicolumn{2}{|c|}{ Total }} & $\mathbf{N}$ & 14 & 16 & & \\
\hline & & & $\%$ & $100.0 \%$ & $100.0 \%$ & & \\
\hline
\end{tabular}

*: Significant difference, $* *$ : Highly significant difference

\section{DISCUSSION}

Clinically significant depression is present in one of every four people with type 2 diabetes mellitus (T2DM). Depression increases the risk of the development of T2DM and the subsequent risks of hyperglycemia, insulin resistance, and micro- and macrovascular complications. Conversely, a diagnosis of T2DM increases the risk of incident depression and can contribute to a more severe course of depression. This linkage reflects a shared etiology consisting of complex bidirectional interactions among multiple variables, a process that may include neurohormonal dysregulation, weight gain, inflammation, and hippocampal structural alterations ${ }^{(7)}$.

This comparative cross-sectional study was carried out on 90 adults divided into three groups, 30 patients with type 2 diabetes mellitus with normal BMI, 30 obese individuals without DM and 30 obese type 2 diabetic patients for highlighting the relationship between type 2 diabetes and obesity with depression.

Our study revealed that age was $51.60 \pm 14.28$, $42.26 \pm 12.21$ and $51.93 \pm 9.89$ respectively and Group B was significantly younger than the other two groups with no significant difference between them. As regard sex distribution, there was no significant difference among groups and male/female were distributed nearly even, also no significant difference was found as regard education level or smoking but as regard employment it was significantly associated with Group B. In the study of Naja et al. ${ }^{(8)}$, out of 2448 participants, 378 (15.4\%) reported depressive symptoms. Patients with selfreported depressive symptoms had lower average age than those with no symptoms (44.8 vs 52.9 years, respectively). There was a statistical gender differences with regards to the prevalence of depressive symptoms. The number of Qatari women with the depressive symptoms $(69.6 \%)$ was higher than that in men (30.4\%). Higher percentage of patients with depressive symptoms received high education $(\mathrm{p}<0.001)$.

The current study showed that no significant difference was found between groups as regard disease duration or DM treatment and also complication but as regard comorbidity Group $\mathrm{C}$ was significantly associated with comorbidity. In the study of Riaz et al. (9), more than three-fourths of the participants $(77.2 \%)$ presented with 1 or more comorbidities. Among the 
comorbidities hypertension (53.2\%), dyslipidemia $(44.9 \%)$, osteoarthritis $(16.4 \%)$, and ischemic heart disease $(10.7 \%)$ are notable. Also, Habtewold et al. ${ }^{(10)}$ demonstrated that one hundred forty-five patients (43.2 $\%$ ) were on oral hypoglycemic treatment, $78.3 \%$ $(\mathrm{n}=141)$ had cardiovascular diseases (hypertension and heart failure), and $69.7 \%(n=140)$ had diabetic retinopathy. More than half $(58.7 \%, \mathrm{n}=155)$ of study participants reported 1 to 2 comorbid disease (mean $\pm \mathrm{SD}, 1.1 \pm 0.9$ ).

According to study of Gupta et al. ${ }^{(11)}$ among 250 type 2 diabetic patients had a mean $( \pm \mathrm{SD})$ age of 53.6 $( \pm 9.1)$ years and $\mathrm{HbA} 1 \mathrm{c}$ of $55.1 \pm 6.8 \mathrm{mmol} / \mathrm{mol}(7.2 \pm$ $0.6 \%)$. Cognitive impairment was present in 57 (22.8\%) participants. In the middle-age subgroup, cognitive impairment was higher $(23.9 \%)$ than those in the fourth decade $(6.3 \%)$, but comparable $(24.0 \%)$ to the older age (60-70 years).

Our study agrees with Salinero-Fort et al. ${ }^{(12)}$ who showed that coexistence of mental disorders such as depression is considerably more frequent in people with T2DM than in the overall population, with a prevalence ranging from $15 \%$ to $24 \%$ and an incidence rate of depression during the first year after initiation of oral antidiabetic treatment of 12.61 per 1000 personyears. In addition, patients with diabetes and mental disorders show poorer compliance with treatment recommendations than patients with T2DM without depression, and more frequently have cardiovascular risk factors such as smoking, obesity, sedentary lifestyle and poor glycemic control, which can impact on their health-related quality of life.

Our study revealed that the majority of our studied group had BMI $>35$. Grade and overall depression was significantly associated with BMI >35 group. Grade and overall depression was significantly associated with BMI >35 group in group C but overall, only in group $\mathrm{B}$, and also depression was more frequent with females. These results are in accordance with Singh et al. ${ }^{(13)}$, as prevalence of obesity increased from $25.4 \%$ among those with no depressive symptoms to $57.8 \%$ among those with moderate to severe depression. Independent of obesity, depression was associated with significant reductions in frequency of moderate (4.6 vs 5.4 times per week) or vigorous $(2.8$ vs 3.7 times per week) physical activity. Depression was associated with significantly higher daily caloric intake (1831 vs 1543) among those with BMI over 30. Also, Pereira-Miranda et al. ${ }^{(14)}$ revealed that overweight and obesity were assessed by body mass index. People with obesity were $32 \%$ more likely to have depression compared to those who were eutrophic $(\mathrm{PR}=1.32 ; 95 \%$ confidence interval $[\mathrm{CI}], 1.26-1.38)$.

\section{CONCLUSION}

Type 2 diabetes mellitus and morbid obesity (BMI $>35$ ) were associated with high prevalence of depression. It is evident that several modifiable and non-modifiable risk factors play an important role in the pathogenesis of diabetes and depression among population. Therefore, this study will have important implications for future research and public health guidance.

\section{Financial support and sponsorship: Nil. Conflict of interest: Nil. REFERENCES}

1. Alharbi K, Khan I, Munshi A et al. (2014): Association of the genetic variants of insulin receptor substrate 1 (IRS-1) with type 2 diabetes mellitus in a Saudi population. Endocrine, 47(2):472-477.

2. World Health Organization (2015): The epidemiology and impact of dementia. Current state and future trends. http://www.who.int/mental__ health/neurology/dementia/ thematic_briefs_dementia/en/. Accessed: 19 October 2019.

3. Al-Rubeaan K (2010): Type 2 diabetes mellitus red zone. Int J Diabetes Mellitus, 2(1): 1-2.

4. Golden S, Williams J, Ford D et al. (2004): Depressive symptoms and the risk of type 2 diabetes: the Atherosclerosis Risk in Communities study. Diabetes Care, 27(2): 429-435.

5. Leitner D, Frühbeck G, Yumuk V et al. (2017): Obesity and type 2 diabetes: two diseases with a need for combined treatment strategies-EASO can lead the way. Obesity Facts, 10(5): 483-492.

6. Darwish L, Beroncal E, Sison M et al. (2018): Depression in people with type 2 diabetes: current perspectives. Diabetes, Metabolic Syndrome and Obesity: Targets and Therapy, 11: 333-38.

7. Srikanth V, Sinclair A, Hill-Briggs F et al. (2020): Type 2 diabetes and cognitive dysfunction-towards effective management of both comorbidities. The Lancet Diabetes \& Endocrinology, 8(6): 535-545.

8. Naja S, Al Kubaisi N, Singh R et al. (2021): Screening for antenatal depression and its determinants among pregnant women in Qatar: revisiting the biopsychosocial model. BMC Pregnancy and Childbirth, 21(1): 1-12.

9. Riaz B, Selim S, Neo M et al. (2021): Risk of depression among early onset type 2 diabetes mellitus patients. Dubai Diabetes and Endocrinology Journal, 21: 1-11.

10. Habtewold T, Alemu S, Haile Y (2016): Sociodemographic, clinical, and psychosocial factors associated with depression among type 2 diabetic outpatients in Black Lion General Specialized Hospital, Addis Ababa, Ethiopia: a cross-sectional study. BMC Psychiatry, 16(1): 1-7.

11. Gupta A, Gupta Y, Anjana $R$ et al. (2021): Association of cognitive impairment with sleep quality, depression and cardiometabolic risk factors in individuals with type 2 diabetes mellitus: a cross sectional study. Journal of Diabetes and its Complications, 35(8):107970.

12. Salinero-Fort M, Gómez-Campelo P, San Andrés-Rebollo F et al. (2018): Prevalence of depression in patients with type 2 diabetes mellitus in Spain (the DIADEMA Study): results from the MADIABETES cohort. BMJ Open, 8(9): 20768.

13. Singh H, Raju M, Dubey V et al. (2014): A study of sociodemographic clinical and glycemic control factors associated with co-morbid depression in type 2 diabetes mellitus. Indian Journal of Psychiatry, 23: 134-142.

14. Pereira-Miranda E, Costa P, Queiroz V et al. (2017): Overweight and obesity associated with higher depression prevalence in adults: A systematic review and meta-analysis. Journal of the American College of Nutrition, 36: 223- 233. 